\title{
Roles of Modern Information Technology in Graduate Training
}

\author{
Ruixian Li \\ School of Transportation and Vehicle Engineering \\ Shandong University of Technology \\ Zibo 255049, China \\ E-mail: 1rx@sdut.edu.cn \\ Song Gao \\ School of Transportation and Vehicle Engineering \\ Shandong University of Technology \\ Zibo 255049, China
}

Innovative Plan Project of Shandong Graduate Education, Project No: SDYY06057

\begin{abstract}
Introduction of information technology into the education field has greatly enriched teaching content and forms, and facilitated transformation of teaching mode, teaching approaches and training concepts. Especially for training of graduates, its introduction seems extraordinarily prominent. In this paper, the authors will analyze and discuss positive roles of information technology in graduate training.
\end{abstract}

Keywords: Information technology, Graduate training

Graduate training is the highest level in higher education, and assumes the task of training and offering advanced professionals for the society. Masters and doctors from graduate education are not only students in their general meanings, but are important scientific research power. Therefore, graduate education should adapt to social development needs of high technology, integration and informationization, and enable graduates to possess innovative capacity and making required to adapt to development of modern society and modern scientific and technical revolution. When rapid development of information and communications technology poses austere challenges, it also creates extremely advantageous conditions for training that innovative capacity and making of students, creating excellent internal and external environment.

\section{Information technology facilitating changes of innovative concepts of graduates training}

On September $8^{\text {th }}, 2002$, the former Chinese President Jiang Zemin made profound discussion on how to conduct educational innovation in the $100^{\text {th }}$ anniversary of Beijing Normal University. He pointed out, "Educational innovation should be based upon full use of modern scientific and technical means, so as to vigorously improve modernized level of education". Talents required by the information society, should not only concentrate on capacity of storing and exploring knowledge, but mostly on capacity of analyzing and resolving practical issues, on capacity of thinking, analyzing, judging, manifesting and innovating, and on actually operating capacity of resolving problems. This is a sort of innovative talents. Therefore, innovation is the soul of the informationized society, and the objective requirement of modern information technology. In an era of information, information technology changes quickly, and new technologies are continually produced, developed, dropped behind and eliminated. Each moment, new technologies are being renewed with a speed many times that of traditional technologies. Non-innovation means being abandoned, and means impossibility to adapt to requirements of the development of the new era. Thereby, the innovative concept in the information era is comprehensively and deeply influencing Chinese higher education, especially graduate education.

Popularization and application of modern educational technology has realized multi-dimension of teaching and study environment, realized features of students' independent and individualized learning, realized diversified education, and has brought into form the open learner-centered educational mode. This sort of educational mode further improves learners' learning positivity in that, at the time when they receive education, their innovation in knowledge, learning approach, thought and consciousness, and scientific and research capacity is also realized. So their innovative capacity 
is comprehensively cultivated.

\section{Information technology enriching teaching content and changing teaching approaches}

All the following phenomena and facts obstruct training of graduates' innovative capacity, including obsolete teaching content but rigid teaching approach; too much focus on knowledge transmission but ignorance on cultivation of capacity; impossibility of supplement of new views, new content, new ideas and new approaches into teaching materials and teaching content which reflect scientific advancement, and social development; insufficient teaching resources, few opportunities of experiments and practices, as well as poor manipulative ability. Continual blending of information technology and other disciplines generate a large quantity of new interdisciplines, which come forth intermittently as a new teaching content in the higher education. Meanwhile, this sort of blending results in the fact that, other traditional disciplines are based on information technology, and their content and forms are comprehensively updated. Under such a circumstance, information technology enables graduates to swim in a sea of new concepts, new matters and new knowledge, to make analysis and judgment based on the establishment of new thoughts, and to realize their advantage development in the genuine meaning.

Application of information technology has quickened speed of knowledge renewal, and has created new teaching environment. Use of network and multi-media can build a learning environment and tool with abundant information, and strong interaction and reflection, which is helpful for students to conduct independent exploration, experiment and creation, and to shape and develop thought with critique and creativeness.

Improvement of information technology and application of medium technology are much more indicated in the fact that, in practical teaching, teachers apply media for courseware to carry a variety of information, such as comprehensive ability to process words, figures, pictures, flashes, audios, and three-dimension flashes, reflection of objective things with lifelike images, display of fundamental knowledge, key points and difficulties in teaching. Also, such teaching media advantages as PowerPoint, projection, movie, TV, recording, video, and diorama are used to perfect innovative research on teaching approaches in the information technology environment and to provide convenience for enriching and presenting innovation of teaching approaches.

Modern teaching may take several forms to present teaching information. Especially multimedia teaching system has aggrandized new dimensions and directions for teaching and learning, and has generated processing and transmitting modes of teaching information with multicenters, multi-orientations, and wholeness. This helps to improve teaching results and cultivate creative thought. Teaching information resources are without conflict, but with infinite shareablity, so learners can apply any online resources intensively or separately. Development and application of resources are not restrained in terms of time and space.

\section{Information technology renovating teaching manners of teachers and broadening learning manners of graduates}

Chinese traditional teaching is centered with teachers, which emphasizes "Imparting knowledge". However, it seldom pays attention to "Developing ability", which leads to the fact that, creativity and divergent thinking have not deserved their expected status and development space. Information technology will make possible extensive educational interaction and teaching that benefits all, and will realize independent and free choice of students in their learning. With acceleration of informationization progress of education, traditional teaching mode has been greatly impinged, and will get more unlikely to adapt to development of the modern society.

Due to popularization of modern media, all sorts of advanced teaching facilities are introduced into universities, which offer much convenience for front-line teachers, such as courseware making room, electronic lesson preparation room, electronic reading room, digital projection room, multimedia language lab, and multimedia network room, etc, Teaching modes and approaches, as well as teaching means, all take their own forms in the environment of unfolding information technology. Teachers apply information technology into teaching of all disciplines, conduct redesign of teaching, and update their teaching modes increasingly.

Classroom teaching of innovative learning requires teachers to penetrate affective education into all aspects of teaching when imparting knowledge. Teachers should break through limitations of pure concentration on imparting knowledge and developing intelligence, and put onto a crucial position training of students' active study emotion and creative consciousness, so as to enable students to possess active enthusiasm of study and creativeness. Application of modern information media can collect information about students' study in time, so teachers may give them individual tutorials, adjust and control teaching. And teachers can unfold explorative learning, interactive learning, and independent learning, so as to enable students to learn enjoyably and actively, and to be the predominant part.

Interaction between teachers and students can be activated. Teaching is the leading, and learning is the principal part. Interaction between teachers and students, open classroom with cooperative exploration, and active and harmonious atmosphere all indicate transition of teachers from traditional knowledge instructors to promoters of student development. In cooperation, students may develop their creative thought, improve their practical innovative skills and 
foster their cooperative spirit.

\section{Information technology intensifying study independence of graduates}

In the process of study, compared with postgraduates, graduates are more independent. Therefore, training study independence of graduates seems more significant for improving their training quality. Graduate study includes two phases, namely, course study and thesis writing, which have their own particular emphasis. Course study is the primary aspect in mastering basic theories and systematical special knowledge of their majors, and is a significant phase for laying foundations for the following thesis preparation and forthcoming practical job. And it is one of standards for measuring training quality. Thesis writing is a scientific research participated by graduates in person under supervision of their supervisors, and is the primary aspect in training their independent scientific research, and in improving their ability to analyze and resolve practical issues. It is also a comprehensive standard for measuring training quality. In the process of study and scientific research, a great many graduates acquire new knowledge to satisfy their study and scientific research requirements and to promote their own development and perfection in virtue of certain means and approaches without others' teaching and tutorship.

In the information society, information means success, because those with more information will stand at the frontier of scientific and technical development, and may possibly make a hit. However, mastery of advanced information technology is precondition for timely and accurate acquisition of information. As a means of acquiring information, information technology has seemed more and more significant in the study of graduates. Modern scientific intelligence is characterized in large quantities, rapid growth, extensive intercross and perfect secrecy, etc,. In order to rapidly and effectively retrieve and browse relative information, and to screen out useful information therefrom, one should master a variety of capabilities including advanced information technology, such as, capability to read academic works and scientific journals, to retrieve database and search for information on the Internet, to proficiently use various reference books, and to look up references, etc,. These capabilities are decisive in display of graduates' independence and are influential in their study profundity and scope.

\section{Information technology promoting improvement of skills in supervisors and administrative personnel}

By means of mastering information technology and modern educational technology, supervisors of graduates can, on one hand, change traditional teaching approaches, cultivate students' information morality, and set up an independent study environment. At the time when imparting knowledge, they also lay emphasis on sensitivity of information and on activities of information analysis and assessment, and lead students to learning how to analyze, summarize and make use of information. In the process of information generation, exchange and transmission, they inspire students' innovative consciousness and enlighten their innovative intelligence. On the other hand, supervisors should learn to use new thought and technology to make judgment on students' thinking, cognition, and capacity in an era of information.

Administrative personnel in charge of graduate education should also focus on mastering of information technology and skills. The forthcoming graduate education need enlarge its openness to the entire society and the world, make public all useful information resources, realize high shareablity of educational resources, and offer the latest, fastest and most comprehensive information for talent training with the latest technology and means. This requires administrative personnel to possess abundant morality and knowledge about modern information technology, and to familiarize themselves with the latest information technology and means.

In conclusion, modern information technology has profound impact upon Chinese graduate education, and plays a positive part. How to more scientifically and rationally apply it into graduate training so as to facilitate development of their innovative education, this requires graduate educational staff to make further exploration.

\section{References}

Muqi Zhuang. (2006). Innovative Study on Teaching Mode and Teaching Approaches in the Information Technology Environment. Gansu Education, (5), 19 20.

Tao Peng. (2000). Full Application of Information Technology to Make Perfect Graduate Education. Education and Modernization, (2), 19 21.

Wanhong Zhang. (2002). Study and Exploration of Graduate education. Xuzhou: China University of Mining and Technology Press. 